\title{
Anxiety and Depression in Cardiac Inherited Disease: Prevalence and Association With Clinical and Psychosocial Factors
}

\author{
Claire E. O’Donovan ${ }^{\mathrm{a}}$, Jonathan R. Skinner ${ }^{\mathrm{bc}}$, Elizabeth Broadbent ${ }^{\mathrm{a}}$ \\ [a] Department of Psychological Medicine, University of Auckland, Auckland, New Zealand. [b] Green Lane Paediatric \\ and Congenital Cardiac Services, Starship Children's Hospital, Auckland, New Zealand. [c] Department of Paediatrics \\ Child and Youth Health, University of Auckland, Auckland, New Zealand.
}

Clinical Psychology in Europe, 2019, Vol. 1(4), Article e38062, https://doi.org/10.32872/cpe.v1i4.38062

Received: 2019-07-08 • Accepted: 2019-10-28 • Published (VoR): 2019-12-17

Handling Editor: Winfried Rief, Philipps-University of Marburg, Marburg, Germany

Corresponding Author: Elizabeth Broadbent, Department of Psychological Medicine, University of Auckland, Private Bag 92019, Auckland 1142, New Zealand. E-mail: e.broadbent@auckland.ac.nz

\begin{abstract}
Background: The small number of published studies indicate increased rates of anxiety and depression among patients with cardiac inherited diseases (CID). This study aimed to assess the prevalence of anxiety and depression in a New Zealand CID cohort and seek any associations with clinical and psychosocial factors.

Method: Patients on a national CID register were sent a survey; 202 of 563 contactable patients participated (36\% response rate). Ages ranged from 16 to 83 years (median 53). Most had Long QT Syndrome (43\%) or Hypertrophic Cardiomyopathy (34\%). Questionnaires collected demographic and psychological variables, including anxiety (GAD-7), depression (PHQ-9), illness perceptions, perceived risk and social support. The registry supplied clinical and genetic characteristics.

Results: 80 participants (42\%) reported features of anxiety and/or depression. 24 (13\%) reached clinical levels of depression, a greater proportion than that found in the general population. Poorer perceived social support was associated with worse anxiety $(p<.001)$ and depression $(p<.001)$ scores. Reporting more physical symptoms $(\mathrm{p}=.001)$ (commonly not caused by the CID) was associated with poorer depression scores and greater perceived consequences of the CID was associated with greater anxiety scores $(\mathrm{p}<.05)$. Neither anxiety nor depression were associated with time since diagnosis, disease severity or type of disease.

Conclusion: Forty percent of the CID population live with some degree of psychopathology but this did not correlate with disease severity, type of disease nor time since diagnosis. Correlating factors which may be modifiable include illness perceptions, various physical symptoms and social support.
\end{abstract}




\section{Keywords}

generalized anxiety, depression, cardiac inherited diseases, long QT syndrome, hypertrophic cardiomyopathy, health psychology

\section{Highlights}

- Rates of clinical levels of anxiety and depression in this CID sample were $10 \%$ and $13 \%$ respectively.

- Anxiety and depression were not associated with disease type, severity or time since diagnosis.

- Perceived lack of support, consequences, and symptoms were associated with depression and anxiety.

- High rates of anxiety and depression in CID's indicate the need for access to psychological support.

Cardiac inherited diseases are a group of genetic heart conditions that account for many sudden cardiac deaths in individuals aged 1 to 35 years (Bagnall et al., 2016). These conditions generally fall into two categories, channelopathies, which affect the electrical processes of the heart, e.g. Long QT Syndrome (LQTS); and cardiomyopathies which cause the heart muscle to become dysfunctional and electrically unstable e.g. Hypertrophic Cardiomyopathy (HCM). The last decade has seen a dramatic rise in the detection of people with cardiac inherited diseases, which is the result of effective international efforts to reduce sudden deaths in young people (Bagnall et al., 2016; Behr et al., 2008; Hofman et al., 2013). However the psychological impact of such detection has been under researched and is only just starting to be explored. The few studies performed to date suggest these individuals are particularly vulnerable to anxiety and depression, with prevalence rates found to be as high as $38 \%$ and $21 \%$ respectively (Ingles, Sarina, Kasparian, \& Semsarian, 2013; Morgan, O'Donoghue, McKenna, \& Schmidt, 2008; Richardson et al., 2018). These rates are considerably higher than the prevalence of anxiety $(6-9 \%)$ and depressive disorders (5 - 8\%) in general populations (Alonso et al., 2004; Kessler, Chiu, Demler, \& Walters, 2005; Wells et al., 2006). However, the rates are in line with clinical levels of anxiety (20-25\%) and depression (20-40\%) in other cardiac populations (Celano \& Huffman, 2011; Moser, 2007).

Cardiac inherited disease patients have shed some light on why this may be in two qualitative studies (Andersen, Øyen, Bjorvatn, \& Gjengedal, 2008; Subasic, 2013). Patients report that they struggle with the uncertainty of the trajectory of their disease; their increased risk of sudden cardiac arrest; and identifying whether their symptoms are normal or sinister. Patients report a physical burden associated with living with these conditions, including symptoms such as extreme fatigue, palpitations and headaches, and side effects from treatment, which can in some instances get in the way of fulfilling roles at home and/or work or engaging with their social network. 
Greater clinical severity and uncertainty of risk may therefore be associated with psychological outcomes. However, research on other hereditary heart diseases has found that disease severity is not the only predictor of psychological well-being (O'Donovan, Painter, Lowe, Robinson, \& Broadbent, 2016). Physical symptoms (including those unrelated to the heart condition) and illness perceptions also contribute to psychological wellbeing.

It is well accepted that anxiety and depression have a negative influence on patient engagement and clinical outcomes (Andrássy et al., 2007; DiMatteo, Lepper, \& Croghan, 2000; Ziegelstein et al., 2000). Disengagement is particularly unhelpful with cardiac inherited disease because it could impede the detection and management of the heart condition in other family members, and nonadherence can be life-threatening. Therefore it is imperative to gain a better understanding of the psychological impact of these conditions.

The aim of this study was to assess rates of anxiety and depression in the New Zealand cardiac inherited disease population and determine which clinical, demographic and psychological factors were associated with anxiety and depression. This study intentionally focused on factors that may be amenable to amelioration, including illness perceptions and social support, as these factors might help to inform the delivery of psychological interventions for this group (Broadbent, Ellis, Thomas, Gamble, \& Petrie, 2009).

\section{Methods}

\section{Study Design and Study Population}

The New Zealand Cardiac Inherited Diseases Register was used to recruit participants (Earle et al., 2019). Eligible patients had a 'definitely' or 'probably' affected clinical status and a genetic status of 'positive', 'uninformative testing' or 'unclassified variant'. Over 15 years of age and proficiency in English were also required. Multi-regional ethical approval was given 9th December 2016 (HDEC Ethics Ref: 16/STH/200)

There were 618 individuals who were identified as eligible; invitations were sent to them in May 2017. However, 55 of these eligible patients were non-contactable due to out of date contact details. A total of 202/563 contacted individuals returned questionnaires within three months (36\% response rate); 361 patients did not participate - 'non-participants'. Demographic information for participants is shown in Table 1. The questionnaire collected data on anxiety and depression and a number of other psychological and clinical variables, as follows. 
Table 1

Demographic and Clinical Variables of Cardiac Inherited Disease Participants

\begin{tabular}{lc}
\hline Characteristic & $\boldsymbol{n}(\%)$ \\
\hline \multicolumn{2}{c}{ Demographic Characteristics } \\
Age: Range (median) & $16-83(53)$ \\
Sex: Female & $103(54.2)$ \\
Ethnicity & \\
NZ European & $151(74.8)$ \\
Māori \& Pacific & $21(10.4)$ \\
Māori & $19(9.4)$ \\
Samoan & $0(0)$ \\
Cook Island Maori & $1(0.5)$ \\
Tongan & $1(0.5)$ \\
Other & $16(7.9)$ \\
Chinese & $3(1.5)$ \\
Indian & $4(2.1)$ \\
Other & $9(4.5)$ \\
\hline
\end{tabular}

\section{Clinical Characteristics}

\section{Inherited cardiac condition}

Long QT Syndrome

$86(42.6)$

Hypertrophic Cardiomyopathy

$69(34.2)$

Dilated Cardiomyopathy

$12(5.9)$

Brugada

$6(3.0)$

Other

$A R V C$

$5(2.5)$

CPVT

$6(3.0)$

Sudden Cardiac Arrest Syndrome

Progressive Cardiac Conduction disorder

$3(1.5)$

Diagnosis missing

$12(5.8)$

\begin{tabular}{lc}
\hline & Clinic Status \\
Definitely affected & $145(71.8)$ \\
Probably affected & $42(21.8)$ \\
\hline
\end{tabular}

Probably affected $42(21.8)$

\section{Positive}

Testing uninformative

Unclassified variant $20(9.9)$ 


\begin{tabular}{lc}
\hline Characteristic & $\boldsymbol{n}(\boldsymbol{\%})$ \\
\hline & Proband \\
True & $121(59.9)$ \\
False & $66(32.7)$ \\
$\beta$-Blocker use & $131(64.9)$ \\
Number of years since diagnosis: Range (median) & $0-51(9)$ \\
\hline
\end{tabular}

Note. Participants $n=202$.

\section{Measures}

Depression was assessed using the Patient Health Questionnaire - 9 (PHQ-9) (Kroenke, Spitzer, \& Williams, 2001). This tool has 9 items that measure how often, in the last two weeks, symptoms of depression have occurred. Responses are recorded on a 4-point scale from 0 - "not at all" to 3 - "nearly every day". The PHQ-9 has been validated against clinical interviews with the following cut-off scores, 5 - 9 'mild cases'; 10 - 14 'moderate cases'; 15 - 19 'moderately severe cases'; and $\geq 20$ 'severe cases' (Kroenke et al., 2001).

Anxiety was measured using the Generalized Anxiety Disorder - 7 (GAD-7) (Spitzer, Kroenke, Williams, \& Löwe, 2006). This assessment tool has 7 items and follows the same structure as the PHQ-9 asking how often symptoms of anxiety have occurred. The GAD-7 has been validated against clinical interviews and the following cut-off scores were established, 5 - 9 'mild cases'; 10 - 14 'moderate cases'; 15 - 21 'severe cases' (Spitzer et al., 2006).

The Brief Illness Perception Questionnaire (Brief IPQ) (Broadbent, Petrie, Main, \& Weinman, 2006) assesses an individual's cognitive and emotional representations of their illness. It contains eight items, with a 0 - 10 response format; assessing people's experience of symptoms (identity); perceptions of personal and treatment control; perceived timeline for the illness, the consequences it has on their life; how concerned they are about it; how much they understand the illness (coherence) and how much it affects them emotionally (emotional representation). The ninth item measures perceptions around cause and was not used in the analysis of this study.

Perceptions of risk were measured using questions based on Bjorvatn and colleagues' (2007) risk questions. One item was used in the analysis, which asked participants to report their perceived chance (0-100\%) of experiencing severe symptoms (e.g. cardiac arrest, sudden cardiac death).

The Problem List is an assessment tool used to identify sources of distress in oncology patients (Holland \& Bultz, 2007). Minor changes were made to the problem list for this study so items were specific to this cardiac population. For example, mouth sores were removed and palpitations were added. It includes practical problems with 'changes to finances', 'work or school' and taking medication; family problems with 'communicating with extended family', 'fulfilling roles within the family' and 'planning to have children'; emotional problems such as 'distress', 'isolated/feeling alone' and 'worried'; physical 
problems such as 'blackouts/faints', 'breathing' 'cold hands and feet', and 'fatigue/tiredness'; and spiritual/religious concerns such as 'loss of purpose' and 'why me?'. Each item was either scored zero if not identified as a problem or 1 if it was identified as a problem. Subtotals for each subscale, and an overall total were then created by the number of problems selected. This tool is a practical way for patients to highlight aspects of their life contributing to their distress levels, so support provisions can be put in place.

The STOP-D is a five item screener used commonly in cardiac populations (Young, Ignaszewski, Fofonoff, \& Kaan, 2007; Young, Nguyen, Roth, Broadberry, \& Mackay, 2015). The five items measure depression, anxiety, stress, anger and social support, participants are asked how much they have been bothered by each item over the last two weeks on a 10-point scale 0 - 'Not at all' to 9 - 'severely'. In this instance the whole measure was not used; we utilized the social support single item which asked how much participants had been bothered by: 'Not having the social support you feel you need?'

Clinical information was extracted from the registry including the type of diagnosis, clinical status (level of certainty of their diagnosis, i.e. definitely affected vs probably affected), genetic status (genotype positive, unclassified variant or uninformative genetic test) and proband status (proband or cascade family member).

Participants responded to clinical questions in the questionnaire including, how long since their diagnosis, whether they had been prescribed $\beta$-blockers, how many of their family members had a cardiac inherited disease diagnosis and whether any family members had died from the condition. Participants also completed demographic questions including age, gender, ethnicity and employment status.

\section{Statistical Analysis}

Missing data were left out of analysis on a case by case basis. Of the 202 participants, 20 had either missing ethnicity and beta-blocker data, clinical, genetic or proband status or did not indicate whether a death had occurred within their family. In total, 17 participants had missing data for anxiety scores, three participants could have scores imputed as no more than two items were missing. In these cases the mean of the completed five items was used as a replacement for the missing items, leaving 14 participants without an anxiety score. In total 28 were missing for depression, 15 participants had scores imputed as no more than three items were missing, again the mean of the remaining items was used as a replacement, leaving 13 participants without a depression score. Of these participants with missing data, 10 did not complete both measures. Analyses were conducted on SPSS version 24 software. Non-parametric tests were used due to non-normally distributed data and medians were used when reporting findings. Spearman correlations were conducted to determine associations between psychological variables and age, anxiety and depression. Mann-Whitney tests were performed to assess differences in anxiety and depression between those taking and not taking $\beta$-blockers, probands versus family members, and those with a definite versus probable clinical status. Comparisons were al- 
so made using the Kruskal-Wallis test to assess whether anxiety and depression differed between genetic status and a death in the family status. Hierarchical multiple regression analysis was performed using the significant variables from the above tests along with age and gender given they are consistently associated with anxiety and depression (Baxter, Scott, Vos, \& Whiteford, 2013; Stordal, Mykletun, \& Dahl, 2003). A total of 160 cases were included in the anxiety regression and 158 for the depression regression. A significance level of .05 was maintained apart from when post-hoc tests were performed during which a Bonferroni correction was made.

\section{Results}

Participants did not differ from non-participants on gender, genetic, proband and clinical status and type of condition; but they did differ based on age $(p<.001)$ and ethnicity $(p$ $<.001$ ). Those who participated were significantly older (median 53 years) compared to those who did not (median 45 years) and New Zealand Europeans were over represented in the study compared to other ethnicities (see Table 1).

Means and standard deviations for all the psychological variables are reported in Table 2.

Table 2

Means and Standard Deviations of the Psychological Variables

\begin{tabular}{lcc}
\hline Psychological Variable & $\boldsymbol{M}$ & SD \\
\hline Anxiety & 3.37 & 4.28 \\
Depression & 4.62 & 4.60 \\
Perceived Social Support & 0.87 & 1.62 \\
Perceived Risk & 32.28 & 30.50 \\
IP Consequence & 3.73 & 2.96 \\
IP Timeline & 9.60 & 1.55 \\
IP Personal Control & 4.30 & 3.27 \\
IP Treatment Control & 4.59 & 3.35 \\
IP Identity & 2.92 & 2.76 \\
IP Concern & 4.50 & 3.23 \\
IP Coherence & 7.17 & 2.54 \\
IP Emotional Representation & 3.30 & 3.12 \\
Problem List - Practical & 1.91 & 2.60 \\
Problem List - Family & 0.69 & 1.09 \\
Problem List - Emotional & 1.62 & 2.61 \\
Problem List - Physical & 2.26 & 2.35 \\
Problem List - Spiritual & 0.21 & 0.52 \\
\hline
\end{tabular}


Depression and anxiety scores ranged from 0 to 21 and 0 to 19 respectively. There were 27/192 (14\%) individuals reporting clinical levels of anxiety and/or depression. Of these individuals $16(8 \%)$ reported clinical levels of both, 4 (2\%) just depression, and 7 (4\%) clinical levels of one and mild levels of the other. There were, 53/192 (28\%) individuals who reported subclinical (mild) levels of anxiety and/or depression. Of these individuals $23(12 \%)$ reported subclinical levels of both, $22(12 \%)$ just mild depression and 8 (4\%) just mild anxiety. Accordingly, 112/192 (58\%) participants fell in the 'non-clinical range. Table 3 displays the proportion of people with at least mild levels of anxiety and depression by type of condition. There was no significant difference in anxiety and depression levels between the two most common conditions LQTS and HCM, $\chi^{2}(1, N=146)=3.87$, $p=.273$. Levels of anxiety and depression did not differ significantly based on gender or age (Table 3).

Table 3

The Proportion of Participants With at Least Mild Anxiety And/Or Depression by the Type of CID Condition

\begin{tabular}{|c|c|c|c|c|}
\hline \multirow[b]{2}{*}{ Condition } & \multicolumn{4}{|c|}{$n(\%)$} \\
\hline & Anxiety only & $\begin{array}{c}\text { Depression } \\
\text { only }\end{array}$ & $\begin{array}{l}\text { Anxiety \& } \\
\text { Depression }\end{array}$ & Total \\
\hline Long QT Syndrome & $6(7)$ & $7(8)$ & $23(27)$ & $36(42)$ \\
\hline $\mathrm{HCM}$ & $1(1)$ & $12(17)$ & $16(23)$ & $29(42)$ \\
\hline DCM & $0(0)$ & $2(17)$ & $1(8)$ & $3(25)$ \\
\hline ARVC & $0(0)$ & $1(20)$ & $1(20)$ & $2(40)$ \\
\hline CPVT & $0(0)$ & $0(0)$ & $1(17)$ & $1(17)$ \\
\hline Brugada & $1(17)$ & $1(17)$ & $0(0)$ & $2(33)$ \\
\hline Sudden Cardiac Arrest Syndrome & $0(0)$ & $1(33)$ & $1(33)$ & $2(67)$ \\
\hline Missing Diagnosis & $0(0)$ & $1(8)$ & $3(25)$ & $4(33)$ \\
\hline Totals & $7(4)$ & $26(13)$ & $46(24)$ & $79(41)$ \\
\hline
\end{tabular}

\section{Anxiety}

Bivariate analyses (Table 4) showed that ethnicity was the only demographic variable associated with anxiety $U=1919.5, z=-2.28, p<.05$. A smaller proportion of New Zealand European participants $(7.5 \%)$ scored above the clinical threshold for anxiety compared to non-New Zealand European participants (17\%). A Kruskal-Wallis test on 'death of a family member due to a cardiac inherited disease' was found to be significantly related to anxiety $H(2)=6.31, p<.05$; however Mann Whitney post hoc tests using a Bonferroni correction did not reach significance between the groups ('yes', 'no', or 'I don't know'). Participants on beta-blockers had significantly greater clinical anxiety $U=2952, z=-2.93$, $p<.01$, compared to participants not on beta-blockers ( $14 \%$ vs $3 \%$ respectively). Clinical, genetic and proband status and channelopathy versus cardiomyopathy were not related 
to anxiety. There was also no significant correlation between anxiety and time since diagnosis.

\section{Table 4}

Bivariate Analyses (Pearson Correlations, Mann-Whitney and Kruskal-Wallis Tests) of the Relationship Between Psychological, Clinical and Demographic Variables With Scores on the Anxiety and Depression Scales

\begin{tabular}{|c|c|c|c|c|}
\hline \multirow[b]{2}{*}{ Spearman Correlations } & \multicolumn{2}{|c|}{ PHQ-9 - Depression } & \multicolumn{2}{|c|}{ GAD-7 - Anxiety } \\
\hline & $r_{s}$ & $p$ & $r_{s}$ & $p$ \\
\hline Age & -.03 & .677 & -.13 & .079 \\
\hline Time since diagnosis & .01 & .939 & -.09 & .230 \\
\hline Percentage of life with diagnosis & .00 & .963 & -.04 & .574 \\
\hline Problem List - Total & .69 & $<.001$ & .66 & $<.001$ \\
\hline Problem List - Physical & .55 & $<.001$ & .44 & $<.001$ \\
\hline Problem List - Emotional & .62 & $<.001$ & .71 & $<.001$ \\
\hline Problem List - Practical & .50 & $<.001$ & .53 & $<.001$ \\
\hline BIPQ - Consequence & .54 & $<.001$ & .53 & $<.001$ \\
\hline BIPQ -Timeline & .01 & .874 & .00 & .968 \\
\hline BIPQ - Personal Control & -.21 & .004 & -.17 & .019 \\
\hline BIPQ - Treatment control & -.02 & .832 & -.08 & .317 \\
\hline BIPQ - Identity & .52 & $<.001$ & .40 & $<.001$ \\
\hline BIPQ - Concern & .45 & $<.001$ & .53 & $<.001$ \\
\hline BIPQ - Understand & .01 & .892 & -.07 & .352 \\
\hline BIPQ - Emotional Representation & .51 & $<.001$ & .62 & $<.001$ \\
\hline Perceived Social Support & .39 & $<.001$ & .48 & $<.001$ \\
\hline Risk Perceptions for severe symptoms (\%) & .38 & $<.001$ & .40 & $<.001$ \\
\hline Mann Whitney Tests & $U(z)$ & $p$ & $U(z)$ & $p$ \\
\hline Beta-blockers (prescribed) & $3179(-2.32)$ & .02 & $2952(-2.93)$ & .003 \\
\hline Parent (not being a) & $2585.5(-1.61)$ & .107 & $2428.5(-1.95)$ & .051 \\
\hline Gender & $3709.5(-1.04)$ & .297 & $3850.5(-0.53)$ & .596 \\
\hline Cardiomyopathy vs Channelopathy & $3923.5(-0.47)$ & .637 & $3839.5(-0.58)$ & .563 \\
\hline Proband (true) & $2885(-2.34)$ & .019 & $3095.5(-1.72)$ & .085 \\
\hline Clinical & $2749(-0.35)$ & .730 & $2372.5(-1.44)$ & .150 \\
\hline Ethnicity (Non-European) & $1935(-2.58)$ & .010 & $1919.5(-2.28)$ & .022 \\
\hline Kruskal Wallis Tests & $H(2)$ & $p$ & $H(2)$ & $p$ \\
\hline Genetic Status & 0.53 & .777 & 0.09 & .958 \\
\hline Death of a family member (Don't know vs No) & 9.42 & .007 & 6.31 & .043 \\
\hline
\end{tabular}

Note. $z=z$ score.

The psychological variables associated with anxiety in the bivariate analyses (Table 4) included the number of physical and practical problems reported, illness perceptions (consequences; personal control; identity, concern, and emotional representation), perceptions of risk and social support. 
Hierarchical multiple regression analysis (Table 5) was conducted and significant variables from the bivariate analyses and age and gender were entered into the model to predict anxiety.

Table 5

Regression Analysis to Investigate Predictors of Anxiety in Individuals With a Cardiac Inherited Disease

\begin{tabular}{|c|c|c|c|c|c|}
\hline \multirow[b]{2}{*}{ Steps } & \multirow[b]{2}{*}{ B } & \multirow[b]{2}{*}{$S E$ B } & \multirow[b]{2}{*}{$\beta$} & \multicolumn{2}{|c|}{ 95\% CI for B } \\
\hline & & & & $\mathbf{L L}$ & UL \\
\hline \multicolumn{6}{|l|}{ Step 1} \\
\hline (Constant) & 5.68 & 1.98 & & 1.78 & 9.59 \\
\hline Age & -0.04 & 0.02 & $-.18^{*}$ & -0.08 & -0.01 \\
\hline Gender & 0.31 & 0.64 & .04 & -0.95 & 1.57 \\
\hline Ethnicity (European vs non-European) & 0.90 & 0.80 & .09 & -0.68 & 2.47 \\
\hline Prescribed Beta-blockers & -1.85 & 0.67 & $-.21^{* *}$ & -3.18 & -0.52 \\
\hline Deaths within the Family - Yes & 0.79 & 0.70 & .10 & -0.59 & 2.18 \\
\hline Deaths within the Family - Don't Know & 0.69 & 0.90 & .07 & -1.09 & 2.47 \\
\hline \multicolumn{6}{|l|}{ Step 2} \\
\hline (Constant) & 3.18 & 1.75 & & -.28 & 6.64 \\
\hline Age & -0.03 & .02 & -.10 & -0.06 & 0.01 \\
\hline Gender & 0.05 & 0.52 & .01 & -0.97 & 1.07 \\
\hline Ethnicity (European vs non-European) & 0.08 & 0.69 & .01 & -1.29 & 1.46 \\
\hline Prescribed Beta-blockers & -1.01 & 0.56 & -.12 & -2.12 & 0.11 \\
\hline Deaths within the Family - Yes & -0.89 & 0.61 & -.11 & -2.09 & 0.31 \\
\hline Deaths within the Family - Don't Know & -0.68 & 0.74 & -.06 & -2.16 & 0.79 \\
\hline PL - Physical symptoms & 0.32 & 0.17 & .17 & -0.01 & 0.65 \\
\hline PL - Practical problems & 0.16 & 0.15 & .10 & -0.14 & 0.46 \\
\hline IP - Personal Control & -0.08 & 0.08 & -.07 & -0.23 & 0.08 \\
\hline IP - Consequence & 0.33 & 0.14 & $.24^{*}$ & 0.05 & 0.61 \\
\hline IP - Identity & -0.11 & 0.15 & -.08 & -0.39 & 0.18 \\
\hline IP - Concern & 0.15 & 0.11 & .12 & -0.08 & 0.37 \\
\hline Risk Perception - Severe symptoms & -0.00 & 0.01 & -.03 & -0.03 & 0.02 \\
\hline Perceived Social Support & 0.79 & 0.17 & $.34^{* * *}$ & 0.47 & 1.12 \\
\hline
\end{tabular}

Note. $\mathrm{CI}=$ confidence interval; $\mathrm{LL}=$ lower limit; $\mathrm{UL}=$ upper limit.

${ }^{*} p<.05 .{ }^{* *} p<.01 .{ }^{* * *} p<.001$.

All significant Brief IPQ items were included in the regression except emotional representation due to its conceptual overlap with the outcome variable. Ethnicity, age, gender, beta-blocker and death of a family member variables were entered in Model 1, and explained $9 \%$ of the variance in anxiety scores $F(6,153)=2.65, p=.018$. Being younger and prescribed beta-blockers $(p=.007)$ were significant independent predictors in Model 1 . 
After entering physical (symptom reports) and practical problems, perceptions of personal control, consequences, identity, concern, risk and social support at Model 2, the total variance explained by the model as a whole was $46 \%\left(R^{2}=.46\right.$, adjusted $\left.R^{2}=.41\right), F(14$, $145)=8.76, p<.001$. The variables in Model 2 explained an additional $37 \%$ of the variance in anxiety, $F_{\text {change }}(8,145)=12.18, p<.001$. In the final model higher perceptions of consequences $(p=.021)$ and perceptions of poorer social support $(p<.001)$ were significantly associated with greater anxiety.

\section{Depression}

Ethnicity was the only demographic variable related to depression $U=1935, z=-2.58, p$ $<.05$ (Table 4). Overall, more non-New Zealand European participants (16\%) reported clinical levels of depression than New Zealand European participants (11\%).

Reports of whether a family member had died due to a cardiac inherited disease was significantly related to depression $H(2)=9.42, p<.01$. Mann Whitney post hoc tests using a Bonferroni correction showed a significant difference between those who had lost a family member and those who reported they had not (13\% vs $11 \%$ respectively reported clinical levels of depression) $U=1963.5, p=.008$; and between those who didn't know if they had lost a family member and those who reported they had not ( $16 \%$ vs $11 \%$ respectively reported clinical levels of depression) $U=812.5, p=.014$.

Those participants prescribed beta-blockers had significantly greater depression scores than those not prescribed them $U=3179, z=-2.32, p<.05$ ( $16 \%$ vs $6 \%$ respectively reported clinical levels of depression). Probands had significantly greater depression scores compared to family members $U=2885, z=-2.34, p<.05$ (14\% vs $8 \%$ respectively reported clinical levels of depression). Clinical and genetic status, channelopathy versus cardiomyopathy, and time since diagnosis were not significantly related to depression.

The psychological variables associated with depression in the bivariate analysis (Table 4) mirrored the anxiety results. Depression scores were significantly related to the number of physical and practical problems participants reported, illness perceptions (consequences, personal control, identity, concern, and emotional representation), perceptions of risk and social support.

A hierarchical multiple regression analysis (Table 6) was conducted using significant variables from the bivariate analysis (again, the emotional representation item from the Brief IPQ was left out due to its conceptual similarity with the outcome variable) and age and gender. Ethnicity, age, gender proband status, beta-blocker and death of a family member variables were entered in Model 1 ; they explained $12 \%$ of the variance in depression scores $F(7,150)=3.04, p=.005$. A death in the family $(p=.006)$ and being a proband $(p=.035)$ were significant variables in Model 1. In Model 2, physical and practical problems, perceptions of personal control, consequences, identity, concern, risk and social support were entered, and the total variance explained by the model as a whole was $50 \%$ $\left(R^{2}=.50\right.$, adjusted $\left.R^{2}=.45\right), F(15,142)=9.39, p<.001$. The variables in Model 2 ex- 
plained an additional $38 \%$ of the variance in depression, $F_{\text {change }}(8,142)=13.21, p<.001$. In the final model greater reported physical problems $(p<.001)$ and perceptions of poorer social support $(p<.001)$ were significantly associated with greater depression scores.

Table 6

Regression Analysis to Investigate Predictors of Depression in Individuals With a Cardiac Inherited Disease

\begin{tabular}{|c|c|c|c|c|c|}
\hline \multirow[b]{2}{*}{ Steps } & \multirow[b]{2}{*}{ B } & \multirow[b]{2}{*}{$S E B$} & \multirow[b]{2}{*}{$\boldsymbol{\beta}$} & \multicolumn{2}{|c|}{ 95\% CI for B } \\
\hline & & & & $\mathbf{L L}$ & UL \\
\hline \multicolumn{6}{|l|}{ Step 1} \\
\hline (Constant) & 7.21 & 2.39 & & 2.48 & 11.94 \\
\hline Age & -0.03 & 0.02 & -.12 & -0.08 & 0.01 \\
\hline Gender & 0.00 & 0.73 & .00 & -1.45 & 1.45 \\
\hline Ethnicity (European vs non-European) & 1.43 & 0.89 & .13 & -0.34 & 3.19 \\
\hline Prescribed Beta-blockers & -1.24 & 0.78 & -.12 & -2.78 & 0.29 \\
\hline Deaths within the Family - Yes & 2.24 & 0.80 & $.24^{* *}$ & 0.66 & 3.82 \\
\hline Deaths within the Family - Don't Know & 1.14 & 1.02 & .09 & -0.88 & 3.16 \\
\hline Proband Status & -1.63 & 0.77 & $-.17^{*}$ & -3.15 & -0.12 \\
\hline \multicolumn{6}{|l|}{ Step 2} \\
\hline (Constant) & 4.04 & 2.13 & & -0.16 & 8.25 \\
\hline Age & -0.02 & 0.02 & -.08 & -0.06 & 0.01 \\
\hline Gender & -0.54 & 0.59 & -.06 & -1.71 & 0.62 \\
\hline Ethnicity (European vs non-European) & 0.48 & 0.78 & .04 & -1.05 & 2.01 \\
\hline Prescribed Beta-blockers & -0.35 & 0.63 & -.04 & -1.60 & 0.90 \\
\hline Deaths within the Family - Yes & 0.42 & 0.68 & .05 & -0.92 & 1.76 \\
\hline Deaths within the Family - Don't Know & -0.33 & 0.83 & -.03 & -1.96 & 1.31 \\
\hline Proband Status & -0.77 & 0.63 & -.08 & -2.01 & 0.47 \\
\hline PL - Physical symptoms & 0.72 & 0.19 & $.35^{* * *}$ & 0.35 & 1.10 \\
\hline PL - Practical problems & 0.08 & 0.16 & .04 & -0.24 & 0.40 \\
\hline IP - Personal Control & -0.07 & 0.09 & -.05 & -0.24 & 0.11 \\
\hline IP - Consequence & 0.29 & 0.16 & .18 & -0.02 & 0.60 \\
\hline IP - Identity & 0.06 & 0.16 & .04 & -0.26 & 0.38 \\
\hline IP - Concern & -0.04 & 0.12 & -.03 & -0.29 & 0.20 \\
\hline Risk Perception - Severe symptoms & 0.00 & 0.01 & .02 & -0.02 & 0.03 \\
\hline Perceived Social Support & 0.75 & 0.18 & $.28^{* * *}$ & 0.39 & 1.12 \\
\hline
\end{tabular}

Note. $\mathrm{CI}=$ confidence interval; $\mathrm{LL}=$ lower limit; $\mathrm{UL}=$ upper limit.

${ }^{*} p<.05 .{ }^{* *} p<.01 .{ }^{* * *} p<.001$.

\section{Discussion}

This study found an increased prevalence of depression and anxiety in patients with a cardiac inherited disease, which supports findings from the small number of earlier stud- 
ies with this patient population. Eighty (42\%) participants had features of at least mild depression and/or anxiety. Time since diagnosis and milder clinical severity did not diminish the likelihood of either anxiety or depression symptoms. The diagnostic levels of depression and anxiety (13\% and $10 \%$ respectively) and subclinical levels of depression $(24 \%)$ in this cardiac inherited disease population were found to be higher than that in general populations (Alonso et al., 2004; Kessler et al., 2005; Wells et al., 2006). Treating psychopathology is important not only for patients' quality of life but evidence suggests even subclinical levels of depression and anxiety can be detrimental for engagement and health outcomes (Lewinsohn, Solomon, Seeley, \& Zeiss, 2000; Roest, Martens, de Jonge, \& Denollet, 2010) and can be risk factors for more severe future psychopathology (Cuijpers \& Smit, 2004).

This study found that perceptions of social support were associated with both anxiety and depression scores in the hierarchical regression models. Perceptions of social support are consistently associated with mental health and wellbeing across many different illness groups including cardiac populations (Hughes et al., 2004; Thoits, 2011). The current study focused on perceived social support, a subjective feeling of being supported, as opposed to received social support, the actual support provided. A perceived lack of support has been found to be a stronger predictor of greater depression than the actual support received, with studies showing a perceived sense of good social support plays a protective role in the association between chronic illness and depression (Santini, Koyanagi, Tyrovolas, Mason, \& Haro, 2015).

Given these heart conditions are hereditary, multiple people within a family can be affected. It would be easy to assume there would be an inbuilt support network for patients, and this is likely the case for the majority of study participants who reported having the social support they felt they needed. However this study suggests an important minority of patients feel they do not have the social support they feel they need and this group is doing poorer psychologically. Further research is needed to better understand perceptions of social support with this specific patient population. Janney (2011) provides some insight in a qualitative study in which LQTS patients reported a perceived lack of emotional support from their social networks due to a poor understanding of the condition (i.e. the absence of visible symptoms).

The number of physical symptoms individuals reported was significantly associated with depression. The association between physical symptoms and depression is also well documented across different conditions, (Katon, Lin, \& Kroenke, 2007) and likely related to the limitations physical symptoms can cause. The items most commonly endorsed by participants in this study were fatigue, palpitations, insomnia, shortness of breath with exercise, and dizziness. These are common symptoms, many of which are reported in primary care populations, and are highly correlated with anxiety and depression (Kroenke et al., 1994). It is therefore important to be aware that patient-reported symptoms may not always be related to their heart condition. Indeed, some of these symptoms would 
not generally be caused by a channelopathy at all, and may in fact provide an indication that anxiety and/or depression is present.

As the Common Sense Model of Illness (CSM) indicates (Leventhal, Meyer, \& Nerenz, 1980), patients attempt to make sense of their symptoms, even mild ones, and may misattribute unrelated symptoms (or side effects from medication) to their cardiac condition which will affect the mental model the patient holds for their cardiac inherited disease. Although certain patient-reported symptoms may not be of direct clinical relevance to the medical management of the heart condition, it is important they get addressed.

Further support for the Common Sense Model was provided by this study, in that illness perceptions were strongly related to psychological distress. The consequence domain was a significant individual contributor to the regression model for anxiety. This is in line with a meta-analysis that included different health conditions, which found the consequence domain consistently predicted the presence of anxiety (Broadbent et al., 2015). Other illness perceptions (personal control, identity and concern) and risk perceptions were associated with anxiety and depression as well. Illness perceptions represent malleable aspects of a patient's experience that could be targeted in an intervention (Broadbent et al., 2009). Longitudinal research is needed to better understand the relationship between perceived social support and illness and risk perceptions and anxiety and depression over time.

This study found that time since diagnosis (median 9 years) and disease severity were not associated with depression or anxiety. It is intuitive to think that the longer someone has a health condition the better they will become at integrating it into their life and coping with its consequences (Morgan et al., 2008). However, studies of other cardiac conditions have shown similar findings (Pelletier et al., 2014), indicating even patients with mild disease can be vulnerable. This study also supports research that found the prevalence of anxiety and depression does not differ between the two most common cardiac inherited diseases, long QT syndrome and hypertrophic cardiomyopathy (Hamang, Eide, Rokne, Nordin, \& Øyen, 2011) which is worth investigating further, given the very different disease trajectories these conditions have. HCM is a progressive condition of heart muscle thickening and dysfunction and reminder symptoms such as shortness of breath on exertion are common in advanced disease. LQTS is non-progressive, and the only symptoms anticipated are syncope, or cardiac arrest. Further research may help to establish which features in common are the most important (such as hereditability and risk of sudden death), as well as the dominant findings here which seem to be common to many diseases in general, such as the importance of a good social support infrastructure.

Although cardiac inherited disease patients are likely to be vulnerable to distress early on (which research shows usually dissipates) (Hendriks et al., 2008), living with these conditions day to day may create an on-going vulnerability to anxiety and depression regardless of severity or how long someone has had the condition. The American Heart Association and American College of Cardiology recommend that there is an integration of 
psychological screening, assessment and intervention into cardiac care across the life span of patients with a congenital heart disease (Warnes et al., 2008). The existing research would suggest it is time to consider similar recommendations for cardiac inherited disease patients.

\section{Clinical Implications}

The fact that $14 \%$ of patients had clinical levels of psychopathology and $28 \%$ had subclinical levels regardless of clinical severity or time with the condition, suggests that psychological support should be made available to this patient population. The finding that nonEuropeans had higher psychological morbidity indicates that ethnic minorities, most notably Māori and Polynesian peoples in this study, will need specific attention.

\section{Limitations}

There are some limitations to this research. Although a 36\% response rate is in accordance with postal and web based surveys (Shih \& Fan, 2008), it means this sample may not be representative of the population as a whole. It is difficult to know whether anxiety and depression are therefore underrepresented or overrepresented in this study. When people are choosing to take part in a voluntary survey they balance the interest, value, and personal relevance of it with the cost in time, energy and resources required to complete it (Groves, Cialdini, \& Couper, 1992). It is feasible that individuals suffering from anxiety and depression could come to a decision from either side of that equation. Compounding this issue of sample representativeness is the fact that younger and ethnic minorities were under-represented and the questionnaire was only provided in English, creating a potential bias around English language proficiency. This is also cross-sectional data and no direction of relationship can be determined.

\section{Conclusion}

This study found anxiety and depression were more prevalent in the cardiac inherited disease population than in the general population and a perceived lack of social support was significantly associated with both. In addition the presence of more physical symptoms (not necessarily specific to the heart condition) was associated with an increased risk of depression and more severe perceptions of the consequences of the heart condition was associated with anxiety. The presence of a mild cardiac phenotype, and having had the condition for a long time do not appear to be protective of poor psychological wellbeing. Future research should investigate these associations in a longitudinal study to help inform psychological interventions with this patient population. 
Funding: Dr. Skinner receives salary support from Cure Kids. Claire O’Donovan receives a PhD scholarship from the University of Auckland.

Competing Interests: The authors declare no conflicts of interest.

Acknowledgments: The authors have no support to report.

Ethics Approval: This study was approved by the Health and Disability Ethics Committee New Zealand and local area health board: number: $16 / \mathrm{STH} / 200$.

Data Availability: Data was collected with the ethics requirement that patients' data is confidential and will not be shared. However any requests for de-identified data should be directed to the corresponding author.

\section{References}

Alonso, J., Angermeyer, M., Bernert, S., Bruffaerts, R., Brugha, T., Bryson, H., . . Vilagut, G. (2004). Prevalence of mental disorders in Europe: Results from the European Study of the Epidemiology of Mental Disorders (ESEMeD) project. Acta psychiatrica scandinavica, 109, 21-27. https://doi.org/10.1111/j.1600-0047.2004.00325.x

Andersen, J., Øyen, N., Bjorvatn, C., \& Gjengedal, E. (2008). Living with long QT syndrome: A qualitative study of coping with increased risk of sudden cardiac death. Journal of Genetic Counseling, 17(5), 489-498. https://doi.org/10.1007/s10897-008-9167-y

Andrássy, G., Szabo, A., Ferencz, G., Trummer, Z., Simon, E., \& Tahy, Á. (2007). Mental stress may induce QT-interval prolongation and t-wave notching. Annals of Noninvasive Electrocardiology, 12(3), 251-259. https://doi.org/10.1111/j.1542-474X.2007.00169.x

Bagnall, R. D., Weintraub, R. G., Ingles, J., Duflou, J., Yeates, L., Lam, L., . . Semsarian, C. (2016). A prospective study of sudden cardiac death among children and young adults. New England Journal of Medicine, 374(25), 2441-2452. https://doi.org/10.1056/NEJMoa1510687

Baxter, A. J., Scott, K. M., Vos, T., \& Whiteford, H. A. (2013). Global prevalence of anxiety disorders: A systematic review and meta-regression. Psychological Medicine, 43(5), 897-910. https://doi.org/10.1017/S003329171200147X

Behr, E. R., Dalageorgou, C., Christiansen, M., Syrris, P., Hughes, S., Tome Esteban, M. T., .. . McKenna, W. J. (2008). Sudden arrhythmic death syndrome: Familial evaluation identifies inheritable heart disease in the majority of families. European Heart fournal, 29(13), 1670-1680. https://doi.org/10.1093/eurheartj/ehn219

Bjorvatn, C., Eide, G. E., Hanestad, B. R., Øyen, N., Havik, O. E., Carlsson, A., \& Berglund, G. (2007). Risk perception, worry and satisfaction related to genetic counseling for hereditary cancer. Journal of Genetic Counseling, 16(2), 211-222. https://doi.org/10.1007/s10897-006-9061-4

Broadbent, E., Ellis, C. J., Thomas, J., Gamble, G., \& Petrie, K. J. (2009). Further development of an illness perception intervention for myocardial infarction patients: A randomized controlled 
trial. Fournal of Psychosomatic Research, 67(1), 17-23.

https://doi.org/10.1016/j.jpsychores.2008.12.001

Broadbent, E., Petrie, K. J., Main, J., \& Weinman, J. (2006). The Brief Illness Perception

Questionnaire. Journal of Psychosomatic Research, 60(6), 631-637.

https://doi.org/10.1016/j.jpsychores.2005.10.020

Broadbent, E., Wilkes, C., Koschwanez, H., Weinman, J., Norton, S., \& Petrie, K. J. (2015). A systematic review and meta-analysis of the Brief Illness Perception Questionnaire. Psychology $\&$ Health, 30(11), 1361-1385. https://doi.org/10.1080/08870446.2015.1070851

Celano, C. M., \& Huffman, J. C. (2011). Depression and cardiac disease: A review. Cardiology in Review, 19(3), 130-142. https://doi.org/10.1097/CRD.0b013e31820e8106

Cuijpers, P., \& Smit, F. (2004). Subthreshold depression as a risk indicator for major depressive disorder: A systematic review of prospective studies. Acta psychiatrica scandinavica, 109(5), 325-331. https://doi.org/10.1111/j.1600-0447.2004.00301.x

DiMatteo, M. R., Lepper, H. S., \& Croghan, T. W. (2000). Depression is a risk factor for noncompliance with medical treatment: Meta-analysis of the effects of anxiety and depression on patient adherence. Archives of Internal Medicine, 160(14), 2101-2107. https://doi.org/10.1001/archinte.160.14.2101

Earle, N. J., Crawford, J., Hayes, I., Rees, M. I., French, J., Stiles, M. K., . . Skinner, J. R. (2019). Development of a cardiac inherited disease service and clinical registry: A 15-year perspective. American Heart fournal, 209, 126-130. https://doi.org/10.1016/j.ahj.2018.11.013

Groves, R. M., Cialdini, R. B., \& Couper, M. P. (1992). Understanding the decision to participate in a survey. Public Opinion Quarterly, 56(4), 475-495. https://doi.org/10.1086/269338

Hamang, A., Eide, G. E., Rokne, B., Nordin, K., \& Øyen, N. (2011). General anxiety, depression, and physical health in relation to symptoms of heart-focused anxiety - A cross sectional study among patients living with the risk of serious arrhythmias and sudden cardiac death. Health and Quality of Life Outcomes, 9(1), Article 100. https://doi.org/10.1186/1477-7525-9-100

Hendriks, K. S., Hendriks, M. M. W. B., Birnie, E., Grosfeld, F. J. M., Wilde, A. A. M., van den Bout, J., . . van Langen, I. M. (2008). Familial disease with a risk of sudden death: A longitudinal study of the psychological consequences of predictive testing for long QT syndrome. Heart Rhythm, 5(5), 719-724. https://doi.org/10.1016/j.hrthm.2008.01.032

Hofman, N., Tan, H. L., Alders, M., Kolder, I., Haij, S. d., Mannens, M. M. A. M., . . Wilde, A. A. M. (2013). Yield of molecular and clinical testing for arrhythmia syndromes. Circulation, 128(14), 1513-1521. https://doi.org/10.1161/CIRCULATIONAHA.112.000091

Holland, J. C., \& Bultz, B. D. (2007). The NCCN guideline for distress management: A case for making distress the sixth vital sign. Journal of the National Comprehensive Cancer Network, 5(1), 3-7. https://doi.org/10.6004/jnccn.2007.0003

Hughes, J. W., Tomlinson, A., Blumenthal, J. A., Davidson, J., Sketch, M. H., Jr., \& Watkins, L. L. (2004). Social support and religiosity as coping strategies for anxiety in hospitalized cardiac patients. Annals of Behavioral Medicine, 28(3), 179-185. https://doi.org/10.1207/s15324796abm2803_6 
Ingles, J., Sarina, T., Kasparian, N., \& Semsarian, C. (2013). Psychological wellbeing and posttraumatic stress associated with implantable cardioverter defibrillator therapy in young adults with genetic heart disease. International fournal of Cardiology, 168(4), 3779-3784. https://doi.org/10.1016/j.ijcard.2013.06.006

Janney, A. (2011). Anxiety in individuals affected by long QT syndrome as experienced by members of an online user group (Doctoral thesis, Philadelphia College of Osteopathic Medicine, Philadelphia, United States). Retrieved from https://digitalcommons.pcom.edu/psychology_dissertations/190

Katon, W., Lin, E. H. B., \& Kroenke, K. (2007). The association of depression and anxiety with medical symptom burden in patients with chronic medical illness. General Hospital Psychiatry, 29(2), 147-155. https://doi.org/10.1016/j.genhosppsych.2006.11.005

Kessler, R. C., Chiu, W., Demler, O., \& Walters, E. E. (2005). Prevalence, severity, and comorbidity of 12-month DSM-IV disorders in the national comorbidity survey replication. Archives of General Psychiatry, 62(6), 617-627. https://doi.org/10.1001/archpsyc.62.6.617

Kroenke, K., Spitzer, R., \& Williams, J. (2001). The PHQ-9. fournal of General Internal Medicine, 16(9), 606-613. https://doi.org/10.1046/j.1525-1497.2001.016009606.x

Kroenke, K., Spitzer, R., Williams, J., Linzer, M., Hahn, S., deGruy, F., III, \& Brody, D. (1994). Physical symptoms in primary care: Predictors of psychiatric disorders and functional impairment. Archives of Family Medicine, 3(9), Article 774. https://doi.org/10.1001/archfami.3.9.774

Leventhal, H., Meyer, D., \& Nerenz, D. (1980). The common sense representation of illness danger. In S. Rachman (Ed.), Contributions to medical psychology (Vol. 2, pp. 7-30). Oxford, United Kingdom: Pergamon Press.

Lewinsohn, P. M., Solomon, A., Seeley, J. R., \& Zeiss, A. (2000). Clinical implications of "subthreshold" depressive symptoms. Journal of Abnormal Psychology, 109(2), 345-351. https://doi.org/10.1037/0021-843X.109.2.345

Morgan, J. F., O'Donoghue, A. C., McKenna, W. J., \& Schmidt, M. M. (2008). Psychiatric disorders in hypertrophic cardiomyopathy. General Hospital Psychiatry, 30(1), 49-54. https://doi.org/10.1016/j.genhosppsych.2007.09.005

Moser, D. K. (2007). "The rust of life": Impact of anxiety on cardiac patients. American fournal of Critical Care, 16(4), 361-369.

O’Donovan, C. E., Painter, L., Lowe, B., Robinson, H., \& Broadbent, E. (2016). The impact of illness perceptions and disease severity on quality of life in congenital heart disease. Cardiology in the Young, 26(1), 100-109. https://doi.org/10.1017/S1047951114002728

Pelletier, R., Lavoie, K. L., Bacon, S. L., Thanassoulis, G., Khan, N. A., Pilote, L., . . Tagalakis, V. (2014). Depression and disease severity in patients with premature acute coronary syndrome. The American fournal of Medicine, 127(1), 87-93.e2. https://doi.org/10.1016/j.amjmed.2013.09.026

Richardson, E., Spinks, C., Davis, A., Turner, C., Atherton, J., McGaughran, J., . . Ingles, J. (2018). Psychosocial implications of living with catecholaminergic polymorphic ventricular tachycardia in adulthood. Journal of Genetic Counseling, 27(3), 549-557. https://doi.org/10.1007/s10897-017-0152-1 
Roest, A. M., Martens, E. J., de Jonge, P., \& Denollet, J. (2010). Anxiety and risk of incident coronary heart disease. Journal of the American College of Cardiology, 56(1), 38-46.

https://doi.org/10.1016/j.jacc.2010.03.034

Santini, Z. I., Koyanagi, A., Tyrovolas, S., Mason, C., \& Haro, J. (2015). The association between social relationships and depression: A systematic review. Fournal of Affective Disorders, 175, 53-65. https://doi.org/10.1016/j.jad.2014.12.049

Shih, T.-H., \& Fan, X. (2008). Comparing response rates from web and mail surveys: A metaanalysis. Field Methods, 20(3), 249-271. https://doi.org/10.1177/1525822X08317085

Spitzer, R. L., Kroenke, K., Williams, J. W., \& Löwe, B. (2006). A brief measure for assessing generalized anxiety disorder: The GAD-7. Archives of Internal Medicine, 166(10), 1092-1097. https://doi.org/10.1001/archinte.166.10.1092

Stordal, E., Mykletun, A., \& Dahl, A. A. (2003). The association between age and depression in the general population: A multivariate examination. Acta psychiatrica scandinavica, 107(2), 132-141. https://doi.org/10.1034/j.1600-0447.2003.02056.x

Subasic, K. (2013). Living with hypertrophic cardiomyopathy. Fournal of Nursing Scholarship, 45(4), 371-379. https://doi.org/10.1111/jnu.12040

Thoits, P. A. (2011). Mechanisms linking social ties and support to physical and mental health. Journal of Health and Social Behavior, 52(2), 145-161. https://doi.org/10.1177/0022146510395592

Warnes, C. A., Williams, R. G., Bashore, T. M., Child, J. S., Connolly, H. M., Dearani, J. A., . . Hijazi, Z. M. (2008). ACC/AHA 2008 guidelines for the management of adults with congenital heart disease: A report of the American college of cardiology/American heart association task force on practice guidelines. Fournal of the American College of Cardiology, 52(23), e143-e263. https://doi.org/10.1016/j.jacc.2008.10.001

Wells, J. E., Oakley Browne, M. A., Scott, K. M., McGee, M. A., Baxter, J., \& Kokaua, J. (2006). Prevalence, interference with life and severity of 12 month DSM-IV disorders in Te Rau Hinengaro: The New Zealand Mental Health Survey. Australian and New Zealand fournal of Psychiatry, 40(10), 845-854. https://doi.org/10.1080/j.1440-1614.2006.01903.x

Young, Q.-R., Ignaszewski, A., Fofonoff, D., \& Kaan, A. (2007). Brief screen to identify 5 of the most common forms of psychosocial distress in cardiac patients: Validation of the screening tool for psychological distress. Fournal of Cardiovascular Nursing, 22(6), 525-534.

https://doi.org/10.1097/01.JCN.0000297383.29250.14

Young, Q.-R., Nguyen, M., Roth, S., Broadberry, A., \& Mackay, M. H. (2015). Single-item measures for depression and anxiety: Validation of the Screening Tool for Psychological Distress in an inpatient cardiology setting. European fournal of Cardiovascular Nursing, 14(6), 544-551. https://doi.org/10.1177/1474515114548649

Ziegelstein, R. C., Fauerbach, J. A., Stevens, S. S., Romanelli, J., Richter, D. P., \& Bush, D. E. (2000). Patients with depression are less likely to follow recommendations to reduce cardiac risk during recovery from a myocardial infarction. Archives of Internal Medicine, 160(12), 1818-1823. https://doi.org/10.1001/archinte.160.12.1818 


\section{EACLIPT}

Clinical Psychology in Europe (CPE) is the official journal of the European Association of Clinical Psychology and Psychological Treatment (EACLIPT).

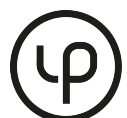

leibniz-psychology.org

PsychOpen GOLD is a publishing service by Leibniz Institute for Psychology Information (ZPID), Germany. 